\section{Crise e saúde mental na adolescência: a história sob a ótica de quem vive}

\author{
Crisis and mental health in adolescence: the \\ story from the perspective of those who live it
}

\section{Crisis y salud mental en la adolescencia: la historia desde la óptica de quien la vive}

Livia Martins Rossi 1

Taís Quevedo Marcolino 1

Marina Speranza 1

Maria Fernanda Barboza Cid 1

\title{
Resumo
}

Este estudo objetivou identificar a percepção de adolescentes que vivenciaram a crise em saúde mental sobre tal experiência, bem como sobre a trajetória percorrida em busca de cuidados. Participaram cinco adolescentes de $16 \mathrm{e}$ 17 anos, usuários(as) de um Centro de Atenção Psicossocial Infantojuvenil (CAPSij), que concederam entrevistas valendo-se de roteiros abertos baseados no método de história oral. As narrativas foram gravadas, transcritas, textualizadas e trabalhadas por meio de análise temática. Os resultados indicaram: (a) a vivência da crise atrelada, principalmente, a sentimentos intensos de angústia, tristeza e desvalia, ideação e tentativa de suicídio - vivenciados como um problema individual; (b) as relações entre pares e familiares desencadeadoras dos processos de crise quando permeadas por diferentes tipos de violência, e como suporte emocional e social, quando imersas em relações de confiança; (c) a trajetória predominante de acesso ao cuidado aconteceu centrada em pontos da Rede de Atenção Psicossocial e não houve relato de internação; (d) as dificuldades no cuidado assentaram-se na adesão ao tratamento, participação em espaços coletivos de cuidado e resistências à medicação. $O$ estudo avança, apresentando a compreensão da crise em saúde mental e dos fatores envolvidos nesta experiência, pela voz dos(das) próprios(as) adolescentes que a vivenciaram, bem como identifica os caminhos trilhados em busca de tratamento e as percepções emergidas da experiência de cuidado nos serviços.

Adolecente; Intervenção na Crise; Serviços de Saúde Mental; Saúde Mental

\section{Correspondência}

M. F. B. Cid

Rua Miguel Petroni 4900, Condomínio Eldorado, casa 143 São Carlos, SP 13563-470, Brasil.

mariafernandacid@gmail.com

1 Universidade Federal de São Carlos, São Carlos, Brasil. 


\section{Introdução}

De acordo com a Organização Mundial da Saúde (OMS) 1, o período da adolescência está localizado dos 10 aos 19 anos de idade, sendo subdividido em fase inicial (dos 10 aos 14 anos) e fase final (dos 15 aos 19 anos). Entretanto, para além das idades, pesquisadores apontam que o conceito de adolescência se transforma com as mudanças da sociedade em um interjogo entre a evolução na estrutura do pensamento, na forma como o indivíduo compreende seu contexto social, em meio às pressões advindas deste mesmo contexto. Assim, as significações atribuídas pela sociedade às diversas realidades possíveis atuam como referências para a constituição dos sujeitos, multiplicando as possibilidades de vivência das adolescências, no plural 2,3,4.

Esse processo complexo de adolescer também é compreendido como um período vulnerável para o desenvolvimento de problemas relacionados à saúde mental 2,4,5. O documento Prevención de la Conducta Suicida 6, relatório recente da Organização Pan-Americana da Saúde (OPAS) em parceria com a OMS, indica o suicídio como a terceira causa de morte entre adolescentes de 10 a 19 anos, em alguns dos 15 principais países americanos, e a segunda causa de morte entre jovens de 15 a 19 anos em nível mundial.

No Brasil, ao longo da história, ações de cuidado em saúde mental voltadas a crianças e adolescentes repousam na omissão, exclusão e assistência fortemente marcada pela institucionalização 7 . Embora estudos relacionados à saúde mental infantojuvenil tenham tido um crescimento após a instituição do Estatuto da Criança e do Adolescente (ECA) e dos Centros de Atenção Psicossociais Infantojuvenis (CAPSij), eles ainda são incipientes considerando-se, especialmente, a população adolescente 8,9,10.

Além disso, os estudos nessa temática correm o risco de permanecerem atrelados aos diagnósticos psiquiátricos e ao cuidado individualizante, sem dialogar com os diversos fenômenos sociais nos quais os adolescentes contemporâneos estão inseridos 7,11. A vivência da crise como uma complexa situação existencial deveria demandar dos serviços especificidades para a ampliação do contato e diminuição dos tempos de latência, no sentido de tornar a intervenção mais precoce 12,13, considerando, inclusive que, para crianças e adolescentes, as situações de emergência psiquiátrica são definidas sempre por outros, possibilitando uma infinidade de julgamentos com relação a cada caso 14 .

Dada a gama de danos que a crise em saúde mental pode repercutir no indivíduo e nas pessoas ao seu redor, constituindo um importante risco ao desenvolvimento e até mesmo à vida, a intervenção imediata é necessária. Entretanto, nota-se que a idade do surgimento dos sintomas nem sempre coincide com a idade do primeiro contato com os serviços de saúde, situação em que provavelmente mais de um episódio já tenha ocorrido 15 .

Além disso, estudos 16,17,18 indicam a prevalência de internações como intervenção prioritária nesses contextos, bem como as dificuldades na implementação de alternativas à atenção hospitalar. Nessa direção, permanecem no cenário nacional, "práticas de atenção à crise predominantemente medicalizantes e hospitalocêntricas que utilizam, inclusive, contenções físicas, mantidas durante longo tempo, e altos níveis de medicação" 17 (p. 161), trazendo questionamentos sobre possíveis violações de direitos. Somase ao processo de judicialização da saúde e da saúde mental a discussão apresentada por Braga \& D’Oliveira 18, de que a internação (em uma enfermaria de psiquiatria em hospital geral com 18 leitos) acontecia essencialmente de forma involuntária, por "distúrbios do comportamento" e "agressividade”, sem que estes comportamentos estivessem, necessariamente, ligados a algum momento de crise, já que foram em grande parte determinados por processos judiciais.

No bojo de estudos com perspectivas que indicam dificuldades na implantação de um cuidado integral e humanizado à crise em saúde mental no adolescente, Shepperd et al. 19, ao avaliarem a eficácia e a aceitabilidade de diferentes modelos de serviços que procuram evitar a internação de crianças e jovens em sofrimento psíquico intenso, concluíram que, ainda que as pesquisas ofereçam poucas orientações para o desenvolvimento e implantação de tais serviços, os jovens que receberam intervenções domiciliares, inclusive em momentos de crise, apresentaram melhoras significativas.

Desse modo, diante da multiplicidade e complexidade dos aspectos ligados à saúde mental de crianças e adolescentes, e dos apontamentos da literatura 16,18,19 para que novas investigações busquem compreender a vivência da crise e sua atenção junto à população de adolescentes, o estudo relatado no presente artigo objetivou identificar a percepção de adolescentes que vivenciaram a crise em saúde mental sobre tal experiência, bem como sobre a trajetória percorrida em busca de cuidados. 


\section{Método}

Trata-se de pesquisa qualitativa, que adotou o método da história oral em suas duas perspectivas: a história oral de vida, para apreender trajetórias significativas em torno dos eventos, com o intuito de explicitar interações entre percursos individuais e processos coletivos; e a história oral temática que parte de um assunto específico previamente estabelecido, por meio de perguntas a serem feitas durante a entrevista 20 . Desse modo, ao buscar apreender a vivência específica dos participantes em torno da crise em saúde mental, buscou-se por narrativas que trouxessem elementos da história de vida dos protagonistas e experiências que culminaram com o evento em questão.

A escolha pelo método foi feita de acordo com o entendimento de que adolescentes, assim como crianças, podem frequentemente ter suas questões reveladas por meio de outras vozes 21 . Na mesma direção, Galhardi \& Matsukura 9 identificaram a importância de dar voz aos adolescentes e de reconhecê-los como cidadãos de direitos nas peculiaridades desta etapa da vida, além de buscar compreender questões intrínsecas a estes sujeitos com base na ótica deles próprios.

Nessa perspectiva, foram ouvidas as histórias de cinco adolescentes, vinculados a um CAPSij de uma cidade de médio porte do interior do Estado de São Paulo, incluídos neste estudo com os critérios de terem idades entre 15 e 18 anos; terem vivenciado ao menos uma situação de crise em saúde mental; estarem em condições de estabelecer uma comunicação verbal compreensível e terem disposição para narrar suas experiências. A indicação dos participantes foi realizada pelos profissionais do serviço, considerando a proximidade destes com os casos e o conhecimento sobre as condições de participação de cada um.

Observa-se, portanto, que o estudo foi realizado com o total de adolescentes que, no período da investigação, estavam vinculados ao CAPSij em questão e que, além de responderem aos critérios, aceitaram participar, fato que é previsto no método de história oral, na medida em que o número de participantes pode ser definido baseando-se nos objetivos do estudo e das possibilidades do contexto de investigação 20 .

O trabalho foi aprovado pelo Comitê de Ética em Pesquisa com Seres Humanos da Universidade Federal de São Carlos sob o número 2.030.751 e autorizado pela Secretaria de Saúde do município em questão. Os(as) adolescentes assinaram um Termo de Assentimento, demonstrando aceite em participar da pesquisa, e seus responsáveis assinaram um Termo de Consentimento Livre e Esclarecido autorizando a participação de cada um.

Os instrumentos de coleta de dados foram: um roteiro aberto de entrevista composto por temas disparadores (motivos que levaram os adolescentes ao CAPSij; trajetória percorrida no(s) momento(s) de crise; o momento da crise e suas percepções sobre esta vivência; percepções e expectativas relacionadas ao cuidado que receberam) e por um questionário de caracterização da amostra com informações sobre o perfil sociodemográfico.

A coleta das histórias ocorreu por meio de um encontro com cada participante. Elas foram gravadas e transcritas na íntegra e, posteriormente, trabalhadas em um processo de lapidação, nomeado de textualização, no qual "são retirados os erros gramaticais, as digressões, as repetições, os cortes de frases ou de ideias e as gírias próprias da linguagem informal" 22 (p. 50), tornando as narrativas lineares e coerentes. Cada textualização foi apresentada aos participantes em um novo encontro, no qual cada um deles pôde ler e propor alterações que foram incorporadas ou subtraídas do texto produzido. Para a validação dos textos, foi solicitado aos participantes que assinassem uma Carta de Cessão, documento que define a legalidade do uso das entrevistas.

A análise dos dados foi feita a partir da leitura atenta e exaustiva das textualizações pelas pesquisadoras envolvidas, no sentido de buscar nos discursos temáticas comuns que pudessem emergir das histórias contadas, conforme preconizado pelo método de análise de conteúdo de Bardin 23, na etapa de análise temática. 


\section{Resultados e discussão}

Participaram deste trabalho quatro meninos e uma menina, caracterizados no Quadro 1, com seus nomes fictícios a fim de preservar suas identidades.

Em termos de escolaridade e trabalho, todos os adolescentes estão em ocupações características deste período de vida para jovens de classes trabalhadoras. Com exceção de Daniel, os demais cursam o Ensino Médio. Dos três jovens que exerciam (ou já haviam exercido) trabalho remunerado, o faziam por meio de uma instituição profissionalizante do município, inclusive Daniel, atualmente estagiário, assumiu esta vaga após o término de seu contrato com a instituição.

Sobre o cuidado em saúde mental, dois participantes apresentaram períodos de crise coincidentes com o início do tratamento no CAPSij, outros dois estavam em tratamento quando ocorreram a última crise, e a menina iniciou o tratamento um mês após a crise.

Os resultados da análise temática explicitaram quatro temas que exploram a vivência da crise em diferentes repercussões na vida cotidiana dos adolescentes: (i) A Crise em Saúde Mental: Intensidade e Sofrimento Psíquico; (ii) Relações Familiares, Interpessoais e a Crise: Rupturas, Afetos, Apoio e Conflito; (iii) $O$ Percurso nos Serviços de Saúde; e (iv) "O Problema É Meu”: A Individualização do Sofrimento.

\section{A crise em saúde mental: intensidade e sofrimento psíquico}

Nas histórias narradas foi possível observar a descrição clara de sensações de desespero, confusão mental, angústia, sentimento de inferioridade, baixa autoestima, medo e descontrole, bem como de comportamentos impulsivos, disparados por tais sensações desconfortáveis, atrelados, muitas vezes, a pensamentos relacionados à morte. Tais vivências revelam uma intensidade de emoções negativas e angustiantes que, a despeito do adolescer desencadear transformações potencialmente geradoras do processo crise/desestabilidade/acomodação à nova realidade 2 , quando somadas a fatores produtores de sofrimento psíquico, aumenta-se a chance de os indivíduos responderem a tal contexto de fragilidade por meio da crise em saúde mental, que pode culminar em ideação ou tentativa de suicídio 15, como nos relatos.

\section{Quadro 1}

Caracterização dos adolescentes.

\begin{tabular}{|c|c|c|c|c|c|}
\hline Participante & Idade (anos) & Escolaridade & Trabalho & $\begin{array}{c}\text { Tempo de vínculo } \\
\text { com o CAPSij }\end{array}$ & $\begin{array}{c}\text { Há quanto tempo } \\
\text { vivenciou a última crise? }\end{array}$ \\
\hline Daniel & 17 & $\begin{array}{c}\text { Superior em andamento - } \\
\text { faculdade de Administração - } \\
\text { primeiro ano }\end{array}$ & $\begin{array}{c}\text { Estagiário no gabinete da } \\
\text { Prefeitura }\end{array}$ & 4 anos & 1 mês \\
\hline Rafael & 17 & $\begin{array}{l}\text { Médio em andamento - } \\
\text { terceiro ano }\end{array}$ & $\begin{array}{l}\text { Já trabalhou como jovem } \\
\text { aprendiz, atualmente } \\
\text { desempregado }\end{array}$ & 3 meses & 3 meses \\
\hline Giovana & 17 & $\begin{array}{c}\text { Médio em andamento - } \\
\text { terceiro ano }\end{array}$ & $\begin{array}{c}\text { Recepcionista de um asilo do } \\
\text { município }\end{array}$ & 3 meses & 4 meses \\
\hline Roberto & 16 & $\begin{array}{l}\text { Médio em andamento - } \\
\text { segundo ano }\end{array}$ & $\begin{array}{c}\text { Ajuda o avô na loja de móveis } \\
\text { usados }\end{array}$ & 1 ano & 1 ano \\
\hline Vinícius & 17 & $\begin{array}{l}\text { Médio em andamento - } \\
\text { segundo ano }\end{array}$ & Não exerce & 4 anos & 1 mês \\
\hline
\end{tabular}

CAPSij: Centro de Atenção Psicossocial Infantojuvenil. 
"Qualquer coisa que acontecia eu achava que eu era um inútil, um imbecil, achava que as coisas nunca iam dar certo, me inferiorizava em todos os aspectos. Parava pra pensar no dia a dia, na vida, no mundo lá fora, $e$ concluía que isso aqui não vale nada também. (...) Um belo dia eu sai pra trabalhar, normalmente, acordei como em um dia normal, com a cabeça cheia de coisas, e simplesmente me deu um estalo assim, eu pensei, por que eu não morro logo? E aí eu fui pra avenida mais movimentada da cidade, em que os carros passam em alta velocidade. Fiquei parado no meio dela e os carros começaram a desviar de mim” (Rafael).

"Acumulou tudo isso e chegou uma hora que eu não aguentava mais, não aguentava mesmo (...). Ai fui atrás de veneno, já que os remédios não tinham dado certo. Só que também não ajudou (...). Eu pensava que era fácil acabar com a sua própria vida, e não é tão fácil. Apesar de ter jeitos diferentes de acabar com a vida e ainda continuar vivendo, acabar com a vida em si é muito difícil. Eu tomei veneno e não resolveu..." (Daniel).

Mundialmente, o suicídio de jovens de 15 a 29 anos fica atrás somente de acidentes automobilísticos. Nesse contexto, sabe-se que para cada suicídio cometido há inúmeras tentativas não registradas nas pesquisas epidemiológicas 6 . A temática do suicídio pode ser explorada sob diferentes perspectivas da sintomatologia psiquiátrica, usualmente identificada na depressão, à significação de falência pessoal e social diante de uma determinada vida que não se deseja ou não se suporta mais 24 .

A literatura em torno da adolescência vem investigando a depressão como condição clínica mais comumente vinculada ao suicídio 25 . Benetti et al. 26 identificaram a depressão como uma das temáticas mais frequentes nos estudos, indicando maior prevalência deste quadro de sofrimento psíquico entre os jovens, em comparação com a população adulta, somada à dificuldade diagnóstica pelas semelhanças entre manifestações clínicas e características comportamentais comuns a esta faixa etária. Além disso, a relação de causalidade em torno da depressão dos adolescentes dialoga com o suporte familiar precário, expressões contemporâneas da cultura e mudanças psíquicas próprias desta fase da vida.

No entanto, para além da análise da manifestação de uma ou mais características que desembocam na formulação de diagnósticos psiquiátricos, levanta-se a reflexão sobre a (in)existência de espaços para o ser adolescente na contemporaneidade. Alguns autores apontam que adolescentes seguem marginalizados das instituições, que pouco têm conseguido criar estratégias que configurem um campo transformador de pertença e de real participação desta população 7,8.

Supõe-se que essa realidade, somada à percepção ainda existente na sociedade de que a adolescência é uma fase, por si só, problemática 2,3, individualiza a questão e fragiliza a criação e a manutenção de redes de apoio, o que pode, também, contribuir para o aumento das dificuldades no processo de busca de novas possibilidades para seguir a vida, potencializando, assim, o sofrimento psíquico.

Tais considerações, disparadas pelos nossos resultados, reforçam a necessidade urgente de implantação de políticas públicas efetivas que considerem a diversidade das possibilidades do ser adolescente, as singularidades desta etapa da vida e, consequentemente, promovam a saúde mental e previnam o suicídio junto a esta população.

\section{Relações familiares, interpessoais e a crise: rupturas, afetos, apoio e conflito}

O valor das relações interpessoais para adolescentes e jovens pode ser visto no estudo de Pessoa \& Libório 27 que, em investigação de âmbito nacional com adolescentes e jovens, identificaram que amigos e família, independentemente de serem monoparentais ou recompostas, possuem maiores índices de confiança, com altos níveis de expectativa dos adolescentes receberem ajuda destas pessoas. Com base em tal resultado, os autores refletem que no processo de nosso desenvolvimento as nossas relações pessoais se imprimem na construção das identidades. Adicionamos que, para além disso, tais relações vivenciadas nos diferentes contextos e cotidianos possíveis dão suporte às possibilidades de engajamento nas atividades significativas, bem como às diferentes expressões do ser, impulsionandonos para a vida 28,29 .

Assim, relacionamentos familiares e interpessoais quando vivenciados como relacionamentos violentos, nas diferentes formas de violência, e inclusive aqueles que repercutem no sujeito como desvalor e abandono objetivo e subjetivo/emocional, foram identificados como fatores de desencadeamento e até de causa do sofrimento psíquico.

“...meu pai passou a não gostar mais de mim e das minhas irmãs. Dai eu vivo brigando com ele, sempre pelo mesmo motivo, por achar que ele não gosta de mim, mas esse dia eu estava com muita raiva. Isso foi em dezembro do ano passado, eu acho. Nós brigamos e eu tomei inseticida" (Giovana). 
"Meu pai passou a me ver como se eu fosse a escória da humanidade. Ele falava dia após dia que eu era um lixo, que eu nunca ia fazer nada correto (...). Essas agressões verbais passaram a agressões físicas, como por exemplo, eu estar dormindo numa boa, uma noite qualquer, e ele chegar com o pé na porta, me tirar da cama, me chutar e me expulsar de casa. Isso aconteceu algumas vezes. E ai eu tinha que dormir na rua, me virar..." (Rafael).

As características do ambiente no qual se desenrola o cotidiano dos sujeitos potencializam-se como fatores de risco à saúde mental na medida em que se tem a presença da violência intrafamiliar (física, psicológica, sexual e negligência) e a falta de acesso a redes sociais de apoio 29,30. Além disso, a exposição a esses fatores por períodos prolongados, além de desencadear a vivência de intenso sofrimento psíquico, está associada à auto e heteroagressividade e a dificuldades no controle dos impulsos com possível comportamento suicida 30 .

Como a outra face da mesma moeda, são os relacionamentos suportivos que amenizam os efeitos das situações adversas vivenciadas, promovendo possibilidades de um crescimento mais saudável ao proporcionar sensações de segurança e confiança.

"Eu tenho um amigo que me ajudou demais! (...) Eu sabia que desde dezembro eu já estava começando com a depressão. Depois que eu admiti isso conversei com ele, e quando eu mais precisei, ele não me deixou sozinho" (Daniel).

“...para falar sobre o que mais me ajudou ao longo de todo o processo, eu penso muito na minha mãe. Porque quando eu falei pra ela sobre o que estava acontecendo, ela realmente me entendeu e procurou me ajudar. (...) ela não me julga, eu penso muito nisso..." (Rafael).

Fernandes \& Matsukura 10, ao buscarem conhecer os contextos de inserção e as relações sociais estabelecidas por adolescentes frequentadores de um CAPSij, identificaram que os profissionais do serviço ocupavam um lugar de destaque na rede de suporte relacional/social dos adolescentes e o serviço foi apreciado como o principal contexto de inserção. Esse lugar de destaque também é dado pelos adolescentes deste estudo.

“...E sou muito grato às profissionais daqui, na verdade minha referência no CAPSij me ajudou no meu amadurecimento" (Daniel).

“...vim pra cá pro CAPS, melhorei aqui. (...) porque aqui eles me ajudaram pra caramba” (Vinícius).

Assim, mais do que pensar aqui na fragilidade de uma sociedade que não oferece múltiplas possibilidades de participação social, educacional e cultural aos adolescentes, nas quais outras pessoas de referência poderiam se oferecer em relações de apoio e confiança, o que se destaca em nosso trabalho e no de Fernandes \& Matsukura 10 é a qualidade das relações nas práticas profissionais nos equipamentos estratégicos de atenção à saúde mental infanto-juvenil, o que sinaliza mais desafios: ampliação do número de serviços e o estabelecimento de cuidado intersetorial e da qualidade relacional, com vistas ao desenvolvimento do outro em suas múltiplas potencialidades, foco da política brasileira de saúde mental e de experiências bem-sucedidas no cuidado à saúde mental, em especial à crise 10,31.

\section{O percurso nos serviços de saúde}

Em nosso estudo, observou-se um itinerário terapêutico consistente para quatro dos cinco participantes (apenas um foi encaminhado aos CAPSij diretamente pela psicóloga da instituição profissionalizante) que, ao buscarem ajuda no serviço de urgência e emergência, a Unidade de Pronto Atendimento (UPA), foram encaminhados para a atenção primária em saúde ou para o serviço de atenção especializada em saúde mental para adultos, o Centro de Atenção Psicossocial de terceiro nível (CAPS III) e, destes serviços, providenciou-se o encaminhamento para o CAPSij. Entretanto, um deles procurou o CAPSij apenas alguns meses após o seu primeiro encaminhamento devido a preconceitos e estigmas atrelados aos usuários deste serviço.

Embora a investigação da resolubilidade da Rede de Atenção Psicossocial (RAPS) não tenha sido foco deste trabalho, observa-se que, neste município de médio porte no interior do Estado de São Paulo, há oferta de diferentes pontos da RAPS e um entrosamento em termos de detecção das demandas em atenção estratégica, de forma que nenhum dos cinco participantes foi internado, apesar da gravidade observada nos momentos das crises. Esse fato contraria o que tem sido verificado em investigações nacionais e internacionais $8,16,17$, que têm demonstrado a prática da internação psiquiátrica como estratégia frequentemente utilizada nos casos de crise em adolescentes, configurando-se como um desafio para o cuidado integral em saúde mental, demandando investigações sobre boas práticas. 
Nessa direção, os resultados do presente estudo destacam a potência da RAPS como política de atenção que, quando estabelecida, é capaz de acolher, referenciar e cuidar, tendo como pano de fundo o território e a prática psicossocial, colocando o sujeito como alvo da ação e, portanto, superando a estratégia manicomial ${ }^{31}$.

Além disso, a partir do momento em que os adolescentes foram acolhidos pelo CAPSij, identificamos, em seus relatos, a valorização dos espaços de escuta individualizada oferecidos pelos profissionais do serviço, conforme trecho a seguir: "Além da médica, eu venho conversar com uma das referências, com quem eu me vinculei desde a primeira vez, com a outra eu ainda não consegui me abrir, meu vínculo é na verdade com a primeira. Ela até aceitou trocar alguns e-mails comigo, já que eu não queria vir" (Daniel).

Uma hipótese é que a escuta qualificada que considera as necessidades individuais nos momentos de crise é tida pelos adolescentes como apoio significativo e organizador, o que torna as relações propícias aos relatos acerca dos sentimentos e angústias experimentados nos momentos mais críticos e abre espaço para a ressignificação da crise, bem como para a criação conjunta de um projeto de cuidado a ser implementado dali em diante.

No entanto, nas histórias dos participantes sobre suas experiências no contexto do CAPSij, observa-se a valorização das estratégias individuais em detrimento das outras formas de ofertas terapêuticas de natureza mais coletiva.

"Acho que já faz um ano que eu vou no CAPS. Desde que eu entrei lá só passo com a psicóloga e com a médica. Nunca participei de outras atividades" (Roberto).

De qualquer forma, de modo geral, a proposição da Política Nacional de Saúde Mental é de que o trabalho nos CAPS deve primordialmente ser desenvolvido em espaços coletivos, como grupos, assembleias e fóruns 31 . Essa estratégia vem se justificando pelo alcance dos diversos espaços passíveis de convivência entre os indivíduos, em uma representação do coletivo dentro do ambiente do serviço, para que este cumpra sua função social de promover integração e participação social.

Taño \& Matsukura 32 , em um estudo que objetivou identificar as características gerais de funcionamento de quatro CAPSij do Estado de São Paulo, encontraram que, a despeito da premissa da Política Nacional de Saúde Mental, o que se observa é um grande contingente de práticas individuais ocorrendo nos CAPSij. As autoras discutem o resultado, sinalizando que a efetivação de coletividades criativas e afetivas com crianças e adolescentes que vivenciam a experiência do sofrimento psíquico é um desafio que deve ser enfrentado.

No entanto, para nós, essa questão favorece a construção de diversas hipóteses como: a oferta individualizada vem sendo percebida como mais adequada à população? Os adolescentes recusam-se a participar de espaços coletivos de cuidado? Os profissionais possuem fragilidades na formação para a condução de espaços coletivos que se ofereçam para a construção de relações de confiança e de apoio para adolescentes?

Assim, acreditamos que novos estudos que se aprofundem nessa questão, no sentido de melhor compreender a percepção dos adolescentes a respeito das estratégias de cuidado que recebem e que gostariam de receber nos CAPSij, bem como sobre a percepção dos profissionais da saúde mental sobre isto, contribuiriam para o melhor entendimento deste resultado.

Além da adesão e da frequência efetiva ao serviço, outra dificuldade identificada abarca o uso da medicação, tanto em termos da adesão como de uma perspectiva psicoeducativa e centrada em como os adolescentes percebem o uso da medicação.

"Minha mãe me trouxe pro CAPS sem eu saber (...). Comecei a frequentar aqui com muita resistência. Tomei medicação só no primeiro mês, e parei por conta própria” (Daniel).

Alguns autores apontam que a rejeição a medicações psiquiátricas pode acontecer por conta da associação com a imagem da loucura, como se a necessidade de adesão à terapia medicamentosa confirmasse um diagnóstico de difícil aceitação. Por outro lado, medidas iatrogênicas podem ser piores do que a vivência do sofrimento psíquico em si, quando não se considera a singularidade dos sujeitos na busca por uma meta principal, que seja a cessação dos sintomas ou a minimização de seus efeitos 15 .

"...Eu continuo indo [ao CAPSij], mas eu acho que eu não preciso de remédio. Eu tomo! Mas não preciso mais (...). Se eu tivesse que falar alguma coisa para as profissionais do CAPS, falaria pra não passarem tanto remédio. Eu acho que eu tomo muito remédio, dá muito sono em mim, e é ruim sentir muito sono (...). Fica difícil fazer as coisas, não dá vontade de ir pra escola..." (Roberto). 
Em relação às oportunidades de troca e escuta, os adolescentes do nosso estudo valorizaram-nas amplamente quando, de acordo com eles, elas existem no contexto do serviço, como já mencionado e discutido neste material, o que reafirma a potência do cuidado psicossocial à crise, exercido no contexto da vida e estabelecido em rede.

Entretanto, na dinâmica do processo de cuidado, os participantes parecem demandar ainda mais espaços de escuta e participação, na medida em que suas dificuldades relacionadas ao excesso de medicação ou o não desejo de estar nas atividades oferecidas no CAPSij pareceram ser pouco consideradas, configurando, talvez, uma necessidade de ampliação das oportunidades de participação ativa dos usuários no serviço, realidade que pode ser objeto de estudos futuros que se debrucem com mais ênfase sobre esta questão, visando à melhor compreendê-la sob a luz da atenção psicossocial a adolescentes.

\section{“O problema é meu": a individualização do sofrimento}

Os adolescentes abordaram a crise e seu entorno de forma individualizada, tratando-a como uma questão essencialmente interna, como algo que criaram e que, portanto, devem superar sozinhos. Algumas vezes, inclusive, culpabilizando-se pelo ocorrido.

"O fato de eu estar bem ou mal está ligado somente a mim. É claro que tem coisas que acontecem no dia a dia que deixam a gente mal ou bem, mas of fato de eu estar bem ou mal da cabeça, se atribui única e exclusivamente a mim" (Rafael).

Essa visão individual do sofrimento vivenciado pelos jovens tem como hipótese o modo como a sociedade, de forma geral, concebe a juventude e suas questões. O entendimento da adolescência como fase "problemática", de rebeldia e questionamentos infundados a respeito do sentido da vida, que "vai passar", pode contribuir para o aumento das proporções que alcançam os processos de patologização da juventude, distorcendo as necessidades legítimas de atenção e intervenções em saúde. Dessa forma, os jovens refletem seus valores e reproduzem a ideia de que necessitam sanar suas próprias angústias e as que eles supostamente causam nas pessoas mais próximas, de forma solitária e com uma urgência, por vezes, fatal 2,11.

No bojo da responsabilização individual, aparecem nos relatos a resistência dos jovens em acreditar que suas questões teriam solução e, especialmente, que poderiam receber ajuda em meio ao que estavam vivendo.

“...e eu de novo não queria admitir que precisava de ajuda (...). Inclusive eu achava que ninguém podia ajudar" (Daniel).

Supõe-se que essa percepção em relação ao próprio sofrimento e a possibilidade de cuidar dele tenha a ver, também, com a ausência de espaços percebidos como apoio, especialmente para tratar questões emocionais. Assim, acredita-se que tal resultado reafirma a necessidade de que os que participam dos diversos contextos de vida com adolescentes estejam atentos às vivências destes indivíduos e às formas como elas os afetam. A complexidade do adolescer e do sofrimento psíquico também reside nas diversas tonalidades existentes entre o pólo de que a "adolescência é assim mesmo" e o outro, de que a medicação em si resolve, reduzindo a crise à desordem biológica, desconsiderando o efeito dos eventos ocorridos ao longo da vida, e minimizando o saber individual sobre o próprio sofrimento.

Esse tema levanta questionamentos direcionados às mudanças nos serviços, de superação de práticas exclusivamente médico-centradas, sintoma-centradas, para práticas que consigam dar movimento ao enredo que permeia os sentidos sobre a crise vivenciada pelos sujeitos que experimentam o sofrimento psíquico, especialmente os adolescentes, com vistas às possibilidades de amenizar as repercussões destas vivências 11,12,15. E também questionamentos direcionados ao modus operandi social, que reduz as vivências em espaços coletivos, não percebidos (e não efetivados de fato) como espaços de apoio e de produção de saúde mental, sejam eles no campo da educação, da cultura, do esporte 10,29, além do enfrentamento de situações de violência à criança e ao adolescente, ainda muito socialmente naturalizadas 17,33 . 


\section{Considerações finais}

O objetivo deste trabalho foi identificar a percepção de adolescentes que vivenciaram a crise em saúde mental sobre tal experiência, bem como sobre a trajetória percorrida em busca de cuidados, obtendo resultados que revelaram contextos de intenso sofrimento psíquico nos quais são experimentadas sensações de desespero, confusão mental, angústia, sentimento de inferioridade e desvalor, medo e descontrole, desesperança perante a dificuldade intensa de produção da própria vida culminando em pensamentos de morte, ideação e tentativas de suicídio e/ou na apresentação de sintomas psicóticos caracterizados por sentimentos de persecutoriedade e alucinações.

As relações entre pares e familiares próximos foram identificadas tanto como desencadeadoras de estresse e contribuíram para o sofrimento psíquico vivenciado, ao se configurarem violentas, em suas mais variadas formas, ou com rupturas constantes, quanto como fatores protetivos ao gerarem sentimentos de segurança e de possibilidades de confiança, suporte e apoio nos momentos de enfrentamento das dificuldades.

A trajetória entre serviços de saúde nas situações de crise vivenciadas pelos participantes deste estudo respeitou primordialmente o circuito UPA-CAPS III-CAPSij, o que demonstrou a potencialidade da rede na detecção de casos com demanda de ações estratégicas. Não houve internação psiquiátrica em nenhum dos casos acompanhados e as ações de acolhimento e escuta qualificada nos momentos de crise foram valorizadas pelos adolescentes. Entretanto, dificuldades também foram apontadas pelos mesmos, e giraram em torno da adesão ao tratamento, às ofertas terapêuticas coletivas e ao uso da medicação.

O trabalho apresenta limitações principalmente pelo número reduzido de participantes e do recorte ocasionado pelo local de estudo, por se tratar de município de médio porte com apenas um CAPSij. Entretanto, a presente investigação possibilitou emergir elementos que poderão contribuir com as futuras reflexões sobre os processos de atenção em saúde mental de adolescentes (da promoção ao cuidado estratégico), bem como levantou outras questões de pesquisa a serem exploradas em estudos futuros, no sentido de ampliar o olhar e a atenção à adolescência atravessada pelo sofrimento psíquico, como: Quais aspectos estão presentes em boas práticas de cuidado em saúde mental a adolescentes em espaços coletivos? Quais aspectos são valorizados por adolescentes que vivenciaram o cuidado em saúde mental para boas práticas nos serviços?

Sinaliza-se, ainda, a relevância de processos investigativos de natureza participativa que reconheçam a voz dos próprios adolescentes, compreendendo-os como detentores do conhecimento mais genuíno sobre suas vivências de sofrimento psíquico e possuidores do direito de participarem da construção das ações coletivas que visem ao seu próprio cuidado.

Acreditamos que estudos dessa natureza oferecem elementos importantes para compreender as perspectivas dos adolescentes, bem como da atenção oferecida, além de subsidiar avaliações de intervenções e promover a reflexão para o planejamento de políticas públicas mais efetivas, valorizadoras de práticas de cuidado que promovam a participação e a saúde mental dos adolescentes em espaços de criação e instauração de projetos de vida. 


\section{Colaboradores}

L. M. Rossi colaborou no desenvolvimento do estudo, confecção e revisão do manuscrito. T. Q. Marcolino participou da confecção do manuscrito, especialmente nas seções de introdução e apresentação dos resultados e discussão, além da revisão do texto final. M. Speranza contribuiu na seção de introdução, nas fases de revisão e formatação do manuscrito. M. F. B. Cid participou e orientou o processo de desenvolvimento do estudo, além de ter colaborado na confecção e revisão do manuscrito.

\section{Informações adicionais}

ORCID: Lívia Martins Rossi (0000-0001-93788885); Taís Quevedo Marcolino (0000-0002-96945118); Marina Speranza (0000-0003-1186-1386); Maria Fernanda Barboza Cid (0000-0002-01990670).

\section{Agradecimentos}

À Profa. Dra. Thelma Simões Matsukura, pelo apoio teórico-metodológico na fase de desenvolvimento e aprimoramento do projeto de pesquisa relacionado a este estudo. À Coordenação de Aperfeiçoamento de Pessoal de Nível Superior (Capes) pelo financiamento.

\section{Referências}

1. Organização Mundial da Saúde. Saúde para os adolescentes do mundo: uma segunda chance na segunda década. Genebra: Organização Mundial da Saúde; 2014.

2. Ozella S. Adolescência: uma perspectiva crítica. In: Contini MLJ, Koller SH, organizadores. Adolescência e psicologia: concepções, práticas e reflexões críticas. Rio de Janeiro: Conselho Federal de Psicologia; 2002. p. 16-24.

3. Freitas MV. Juventude e adolescência no Brasil: referências conceituais. São Paulo: Editora Ação Educativa; 2005.

4. Moreira JO, Rosário AB, Santos AP. Juventude e adolescência: considerações preliminares. Psico (Porto Alegre) 2011; 42:457-64.

5. Avanci JQ, Assis SV, Oliveira RVC, Ferreira RM, Pesce RP. Fatores associados aos problemas de saúde mental em adolescentes. Psicol Teor Pesqui 2007; 23:287-94.

6. Organización Mundial de la Salud; Organización Panamericana de la Salud. Prevención de la conducta suicida. Washington DC: Organización Panamericana de la Salud; 2016.

7. Taño BL. A constituição de ações intersetoriais de atenção às crianças e adolescentes em sofrimento psíquico [Tese de Doutorado]. São Carlos: Universidade Federal de São Carlos; 2017.
8. Silva JF, Cid MFB, Matsukura TS. Atenção psicossocial de adolescentes: a percepção de profissionais de um CAPSij. Cad Bras Ter Ocup 2018; 26:329-43.

9. Galhardi CC, Matsukura TS. O cotidiano de adolescentes em um Centro de Atenção Psicossocial de Álcool e outras Drogas: realidades e desafios. Cad Saúde Pública 2018; 34:e00150816.

10. Fernandes ADSA, Matsukura TS. Adolescentes no CAPSi: relações sociais e contextos de inserção. Rev Ter Ocup USP 2015; 26:216-24.

11. Vicentin MCG, Gramkow G. Que desafios os adolescentes autores de ato infracional colocam ao SUS? Algumas notas para pensar as relações entre saúde mental, justiça e juventude. In: Lauridsen-Ribeiro E, Tanaka OY, organizadores. Atenção em saúde mental para crianças e adolescentes no SUS. São Paulo: Editora Hucitec; 2010. p. 337-51.

12. Dell'Acqua G, Mezzina R. Resposta à crise: estratégia e intensionalidade da intervenção no serviço psiquiátrico territorial. In: Amarante PD, organizador. Archivos de saúde mental e atenção psicossocial. Rio de Janeiro: Nau Editora; 2005. p. 161-94. 
13. Ferigato SH, Campos RO, Ballarin ML. O atendimento à crise em saúde mental: ampliando conceitos. Rev Psicol UNESP 2007; 6:31-44.

14. Janssens A, Hayen S, Walraven V, Leys M, Deboutte D, Havenss V. Emergency psychiatric care for children and adolescents: a literature review. Pediatr Emerg Care 2013; 29:1041-50.

15. Carvalho IS, Costa II, Bucher-Maluschke JSNF. Psicose e sociedade: interseções necessárias para a compreensão da crise. Rev Mal-Estar Subj 2007; 7:163-89.

16. Lamb CE. Alternatives to admission for children and adolescents: providing intensive mental health care services at home and in communities. What works? Curr Opin Psychiatry 2009; 22:345-59.

17. Pereira MO. Um olhar sobre a atenção psicossocial a partir do itinerário terapêutico de adolescentes em crise [Dissertação de Mestrado]. Rio de Janeiro: Escola Nacional de Saúde Pública Sergio Arouca, Fundação Oswaldo Cruz; 2013.

18. Braga CP, D'Oliveira AFPL. A continuidade da internação psiquiátrica de crianças e adolescentes no cenário da reforma psiquiátrica brasileira. Interface Comun Saúde Educ 2015; 19:33-44.

19. Shepperd S, Doll H, Gowers S, James A, Fazel M, Fitzpatrick R, Pollock J. Alternatives to inpatient mental healthcare for children and young people. Cochrane Database Syst Rev 2009; (2):CD006410.

20. Meihy JCSB, Holanda F. História oral: como fazer, como pensar. São Paulo: Contexto; 2015.

21. Rhoden SM. A pesquisa com crianças: a criança como sujeito da pesquisa. In: Anais do Seminário Nacional de Arte e Educação. Porto Alegre: Editora da Fundarte; 2012. p. 410-7.

22. Caiado KRM. O aluno deficiente visual na escola: lembranças e depoimentos. Campinas: Autores Associados; 2003.

23. Bardin L. Análise de conteúdo. 5a Ed. Lisboa: Edições 70; 2009.

24. Sampaio MA, Boemer MR. Suicídio: um ensaio em busca de um des-velamento do tema. Rev Esc Enferm USP 2000; 34:325-31.
25. Azevedo A, Matos AP. Ideação suicida e sintomatologia depressiva em adolescentes. Psicol Saúde Doenças 2014; 15:180-91.

26. Benetti SPC, Ramires VRR, Schneider AC, Rodrigues APG, Tremarin D. Adolescência e saúde mental: reisão de artigos brasileiros publicados em periódicos nacionais. Cad Saúde Pública 2007; 23:1273-82.

27. Pessoa ASG, Libório RMC. Nível de confiança de adolescentes e jovens em instituições e processos de resiliência. In: Dell'Aglio DD, Koller $\mathrm{SH}$, organizadores. Adolescência e juventude: vulnerabilidade e contextos de proteção. São Paulo: Casa do Psicólogo; 2011. p. 163-94.

28. Barros JO, Mângia EF. Rede social e atenção às pessoas com transtornos mentais: novo desafio para os serviços de saúde mental. Rev Ter Ocup 2007; 18:135-42.

29. Cid MFB. Cotidiano familiar: refletindo sobre a saúde mental infantil e a prática de atividades familiares. Rev Ter Ocup 2015; 26:428-38.

30. Scivoletto S, Boarati MA, Turkiewicz G. Emergências psiquiátricas na infância e adolescência. Rev Bras Psiquiatr 2010; 32:112-20.

31. Coordenação-Geral de Saúde Mental, Álcool e Outras Drogas, Departamento de Atenção Especializada e Temática, Secretaria de Atenção à Saúde, Ministério da Saúde. Atenção psicossocial a crianças e adolescentes no SUS: tecendo redes para garantir direitos. Brasília: Ministério da Saúde; 2014.

32. Taño BL, Matsukura TS. Os centros de atenção psicossocial infantojuvenis: características organizacionais e oferta de cuidados. Rev Ter Ocup 2014; 25:208-16.

33. Tardivo LSLPC. Violência doméstica contra crianças e adolescentes no contexto brasileiro: discussão a partir de dados da literatura. BIS, Bol Inst Saúde 2014; 15:68-74. 


\section{Abstract}

This study sought to identify adolescents' perception regarding the mental health crises they experienced, as well as their trajectory when seeking care. The participants were five adolescents aged between 16 and 17 years who frequent a Center for Child and Adolescent Psychosocial Care (CAPSij, in Portuguese) who gave interviews following open-ended scripts based on oral history methods. The narratives were recorded, transcribed, rendered into text and analyzed through a thematic analysis. Results indicate: (a) the crisis experience connected, in particular, with intense feelings of anguish, sadness and worthlessness, suicide ideation and attempt - experienced as an individual problem; (b) relationships with peers and family members triggering crisis processes when permeated by different types of violence; and as emotional and social support when immersed in relationships of trust; (c) the predominant trajectory for accessing care was centered in points of the Psychosocial Care Network and there were no reports of hospital admissions; (d) difficulties in care are centered on treatment adhesion, participation in collective care spaces and resistance to medication. This study is an advancement, presenting the understanding of mental health crisis and factors involved in this experience, through the perspective of the adolescents who experienced it, as well as identifying the paths they followed when searching for treatment and the perceptions that emerged from the experience of care in the services.

Adolescent; Crisis Intervention; Mental Health Services; Mental Health

\section{Resumen}

El objetivo de este estudio fue identificar la percepción de adolescentes sobre la experiencia de vivir crisis de salud mental, así como sobre la trayectoria recorrida en búsqueda de cuidados. Participaron cinco adolescentes de 16 y 17 años, usuarios(as) de un Centro de Atención Psicosocial Infantojuvenil (CAPSij), que concedieron entrevistas a partir de guiones abiertos, basados en el método de historia oral. Las narraciones fueron grabadas, transcritas, textualizadas y trabajadas mediante un análisis temático. Los resultados indicaron: (a) la vivencia de la crisis asociada, principalmente, a sentimientos intensos de angustia, tristeza y desprotección, ideación y tentativa de suicidio -vividos como un problema individual; (b) las relaciones entre pares $y$ familiares desencadenantes de procesos de crisis, cuando son permeables a diferentes tipos de violencia; y como apoyo emocional y social, cuando están inmersas en relaciones de confianza; (c) la trayectoria predominante de acceso al cuidado se produjo centrada en puntos de la Red de Atención Psicosocial y no hubo narración de internamiento; (d) las dificultades en el cuidado se asentaron en la adhesión al tratamiento, participación en espacios colectivos de cuidado y resistencias a la medicación. El estudio avanza, presentando la comprensión de la crisis en salud mental y de los factores involucrados en esta experiencia, a través de la voz de los(las) propios(as) adolescentes que la vivieron, así como identifica los caminos recorridos en búsqueda de tratamiento y las percepciones surgidas de la experiencia de cuidado en los servicios.

Adolescente; Intervención en la Crisis; Servicios de Salud Mental; Salud Mental
Recebido em 25/Jun/2018

Versão final reapresentada em 25/Out/2018 Aprovado em 05/Nov/2018 